J.micropalaeontol., 7(1): 53-57, May 1988

\title{
A technique for viewing the same nannofossil specimen in light microscope and scanning electron microscope using standard preparation materials
}

\author{
LIAM T. GALLAGHER \\ Postgraduate Unit of Micropalaeontology, University College London, Gower Street, \\ London WC1E 6BT
}

\begin{abstract}
A new technique for viewing the same nannofossil specimen under the light microscope and scanning electron microscope is described, in which standard preparation materials are used. The applications of this, and previous techniques, are discussed as well as the relevance of these to the elucidation of taxonomic problems.
\end{abstract}

\section{INTRODUCTION}

The use of scanning electron microscopy (SEM) for the study of calcareous nannofossils has become widespread in recent years, but it has been employed in parallel with, and separately from, light microscopy (LM) for the identification of taxa. It is clear that the identification of a specimen on the basis of a single type of micrograph is both undesirable and unsatisfactory. In the past, forms have been identified and elaborately described in the electron microscope with little or no information as to their light microscope characteristics, and vice versa. There is a great difference in resolution between these two viewing media and they provide complementary information. The fact that only surface morphology can be studied in the SEM, while the crystallographic orientation of elements can be observed only in the light microscope, means that it is very difficult to demonstrate the identity of a form first described in the light microscope with one observed with the SEM (Thierstein et al., 1971, p. 501). The two microscopical methods actually complement each other and it is very desirable to examine individual specimens using both techniques.

An early attempt to study the same specimen in first the $\mathrm{LM}$ and then the transmission electron microscope (TEM) was made by Perch-Nielsen (1967) whose method involved chemicals such as Formvar and Methylisobutylketone which are not normally used in calcareous nannofossil analysis, and a copper grid from which co-ordinates could be taken. Moshkovitz (1974) commented that Formvar is apt to deteriorate with time and is prone to damage by the electron beam. The SEM has largely superseded the TEM for calcareous nannofossil work, but even allowing for the elimination of the complex processing for the TEM, there is still no rapid way of locating any individual specimen on the grid. Laing (1974) also had a grid specially manufactured which could be used for Palynology or coccolith study.
Thierstein (op. cit., p. 501) described a method by which a specimen is viewed first in the SEM and then in the LM. The rectangular corner of a cover slip is covered with a dispersion of calcareous nannofossils and then coated with a very thin layer of metal such as gold. Transferral from SEM to LM means that the LM image will be 'coloured' by the coating of metal over the specimens and, as noted by Moshkovitz (op. cit., p. 145 ), charging in the SEM may be a problem with such a thin metal coating and, in addition, relatively complex calculations are required to re-locate specimens in the LM. Moshkovitz (op. cit., pp. 146-147) has also employed the use of a copper grid, onto which the calcareous nannofossils are placed. However, the use of 'Kodak Photo Resist' (KPR) and benzene once again introduces materials not normally utilised in nannopalaeontology. This procedure also requires UV light conditions and the circular grid lacks orientation markers. Moshkovitz (1978) refined his technique by developing a purpose-made cover slip onto which a grid is printed, but the procedure then involves special well slides to hold the cover slip and the use of xylene which is now discouraged for health reasons.

A technique by which the same specimen may be viewed in both LM and SEM is clearly beneficial for the elucidation of taxonomic problems. Such a method which is clean, rapid and accurate, utilising routine materials and therefore inexpensive, is of considerable interest and just such a technique is outlined below.

\section{PREPARATION OF COVER SLIP (See Fig. 1a)}

A circular cover slip (13mm diameter) is used and in order that the position of individual specimens within the assemblage dispersed onto the cover slip can be accurately recorded it is necessary to have an annotated 'grid' on the cover slip which will be visible in both LM and SEM. It is possible to etch the surface of the cover 


\section{Explanation of Plate 1}

Figs. 1a, b. Helicosphaera dinesenii Perch-Nielsen: fig. 1a, SEM, proximal view of a well preserved specimen, UCL-2601-09 (X1875); fig. 1b, LM, phase contrast, direction of view discernible by flange suture being visible in bottom right hand corner of specimen. Same specimen as fig. 1a, UCL-2585-19 (X1802). Shell/Esso North Sea Well No. 49/9-1, depth 2026'. Middle Eocene.

Figs. 2a, b. Chiasmolithus grandis (Bramlette \& Riedel) Radomski: Fig. 2a, SEM, distal view of a well preserved specimen, teeth and central area grill between the bars are clearly seen. Slightly corroded rim, UCL-2601-10 (X1875); fig 2b, LM, phase contrast, the image is good, but detail (teeth \& grill) cannot be seen. Same specimen as fig. 2a, UCL-2585-17 (X1638). ShellEsso North Sea Well No. 49/9-1, depth 2026' Middle Eocene.

Figs. 3a, b. Pontosphaera multipora Roth: fig. 3a, SEM, distal view of a slightly etched specimen, UCL-2423-17 (X2500); fig. 3b, LM, crossed-nicols, good image of pores and extinction figure, but no indication of direction of view. Same specimen as fig. 3a, UCL-2392-23 (X1434). Whitecliff Bay, Bracklesham Group, Selsey Sand Formation, Fisher Bed XVII, 0.5m above base. Middle Eocene.

Figs. 4a, b. Rhabdolithus gladius Locker: fig. 4a, SEM, side view of specimen with a damaged base, UCL-2601-26; (X2500); fig. 4b, LM, phase contrast, distinctive stem but less clear basal area. Same specimen as fig. 4a, UCL-2585-01 (X2286). Shell/Esso North Sea Well No. 49/9-1, depth 2026'. Middle Eocene.

Figs. 5a, b. Micrantholithus aequalis Sullivan: fig. 5a, SEM, corroded specimen, sutures barely visible, UCL-2601-31 (X1250); fig. 5b, LM, phase contrast, sutures much clearer. Same specimen as fig. 5a, UCL-2585-07 (X1556). Shell/Esso North Sea Well No. 49/9-1, depth 2026'. Middle Eocene.

Figs. 6a, b. Isthmolithus recurvus Deflandre: fig. 6a, SEM, oblique top view of well preserved specimen, UCL-2391-17 (X1250); fig. 6b, LM, crossed-nicols, reasonably good image. Same specimen as fig. 6a, UCL-2385-18 (X1638). S136/898, William's Bluff, Oamaru, New Zealand. Late Eocene.

Figs. 7a, b. Zygrhablithus bijugatus (Deflandre) Deflandre: fig. 7a, SEM, side view of a relatively elongate specimen, UCL-2391-09 (X1250); fig. 7b, LM, crossed-nicols, clear outline. Same specimen as fig. 7a, UCL-2385-13 (X1512). S136/898, William's Bluff, Oamaru, New Zealand. Late Eocene.

Figs. 8a, b. Ericsonia formosa (Kamptner) Haq: fig. 8a, SEM, distal view, elements cleary defined, though slightly overgrown in the central area, UCL-2423-02 (X2500); fig. 8b, LM, crossed-nicols, good extinction figure, but no rim detail. Same specimen as fig. 8a, UCL-2392-01 (X1900). Whitecliff Bay, Bracklesham Group, Selsey Sand Formation, Fisher Bed XVII, 0.5m above base. Middle Eocene.

Figs. 9a, b. Reticulofenestra oamaruensis (Deflandre) Stradner \& Edwards: fig. 9a, SEM, distal view of a well-preserved specimen in which the coarsely reticulate grill and high tube cycle are clearly seen, UCL-2391-19 (X1250); fig. 9b, LM, crossed-nicols, very distinctive central area in cross-polarised light. Same specimen as fig. 9a, UCL-2385-20 (X1523). S136/898, William's Bluff, Oamaru, New Zealand. Late Eocene.

Figs. 10a, b. Chiasmolithus solitus (Bramlette \& Sullivan) Locker: fig. 10a, SEM, proximal view of a well-preserved specimen, UCL-2423-11 (X1250); fig. 10b, LM, phase contrast. Same specimen as fig. 10a, UCL-2392-10 (X1560). Whitecliff Bay, Bracklesham Group, Selsey Sand Formation, Fisher Bed XVII, 0.5m above base. Middle Eocene.

Figs. 11a, b. Neococcolithes dubius (Deflandre) Black: fig. 11a, SEM, two specimens showing different states of preservation (X2500); fig. 11b, LM, crossed-nicols, no difference in preservation or specimen orientation can be detected from this image. Same specimen as fig. 11a (X1600). Whitecliff Bay, Bracklesham Group, Selsey Sand Formation, Fisher Bed XVII, 0.5m above base. Middle Eocene. 
A technique for viewing nannofossils

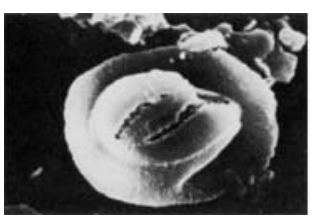

$1 \mathrm{a}$

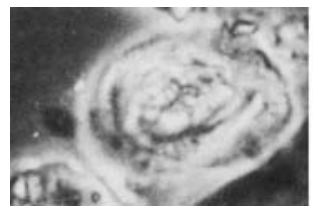

$1 b$

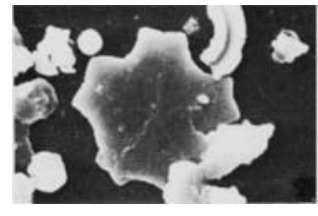

$5 a$

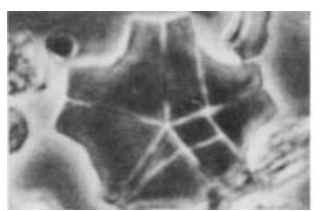

$5 b$

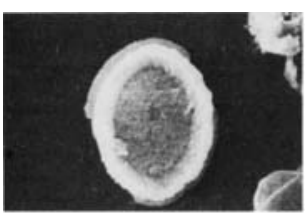

$9 a$

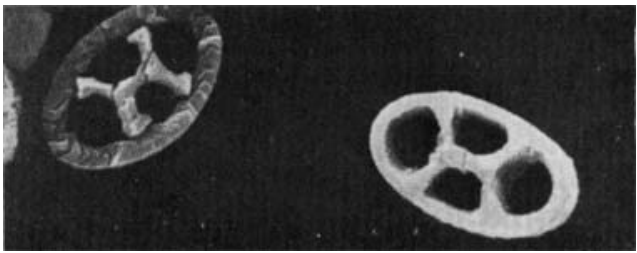

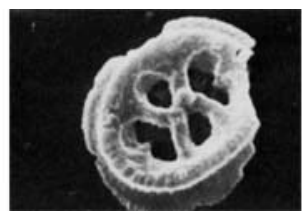

$2 a$

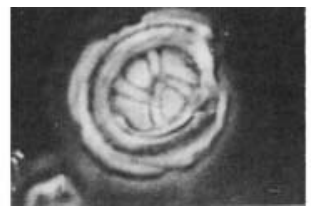

$2 b$

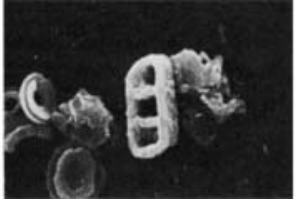

$6 a$

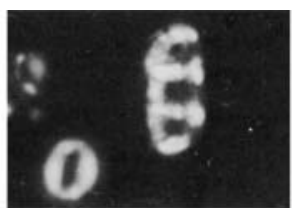

$6 b$

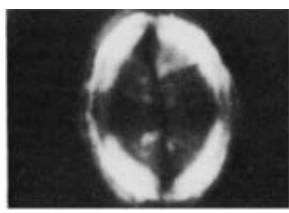

$9 b$
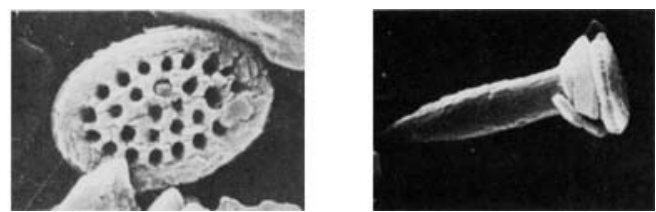

$3 a$

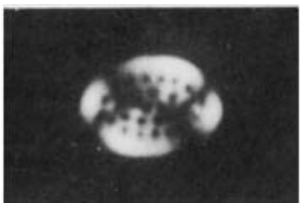

$3 b$

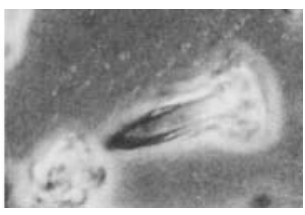

$4 b$
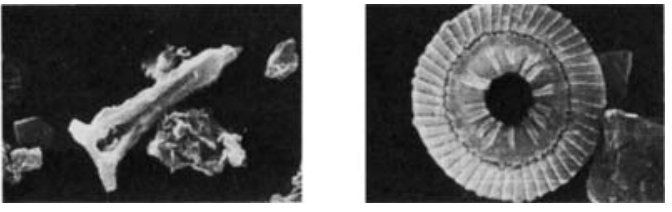

$7 a$

$8 a$
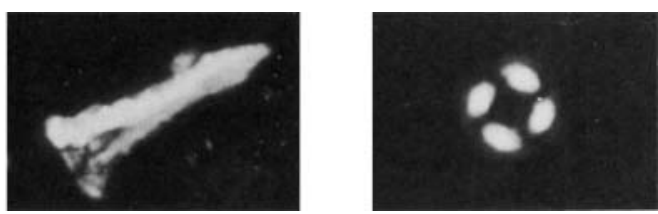

$7 b$

$8 b$
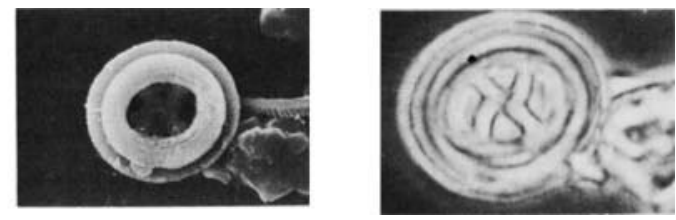

$10 a$

$10 \mathrm{~b}$

$11 a$

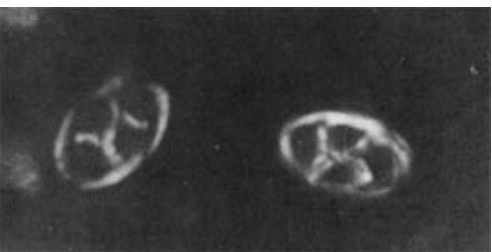




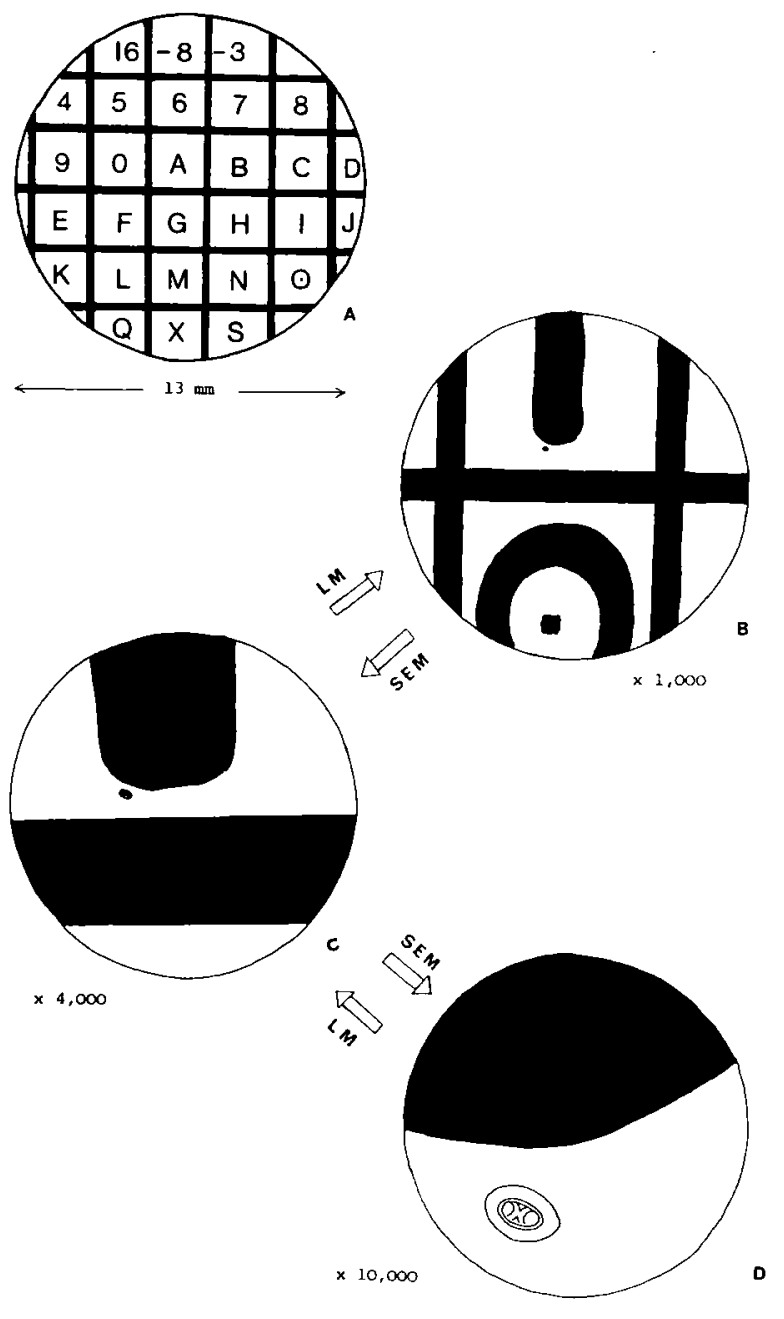

Fig. 1a. Example of the grid system drawn in ink on a $13 \mathrm{~mm}$ diameter cover slip. Any configuration of numbers, letters or symbols can be used to annotate the grid as long as a record is kept of the pattern employed. If a number of samples are being prepared at one time, it is advisable to label the grid on the circular cover slip of each with its relevant sample number, depth, etc., and to use this as part of the annotation.

Figs. 1b, c, d. Light microscope investigation may proceed at a high magnification until a specimen of interest is located. This is photographed and its location noted by moving to progressively lower powers of magnification and plotting its position relative to the grid symbols. Scanning electron microscope investigation begins at a relatively low magnification until the required position on the grid is reached, the magnification is then increased until the individual specimen of interest comes into view. slip with a diamond tipped pen or hydrofluoric acid to produce negative relief, however, the fragile cover slip is easily damaged in this way. The simplest method of applying the 'grid' is to draw it on with a standard technical pen $(0.1 \mathrm{~mm}$ nib). In this way grid lines and labels of any configuration can be produced to suit the investigator's needs. The ink shows up as black lines in the LM and as raised ridges beneath the conductive coating in the SEM (see Fig. 1a). Once a circular cover slip has been prepared in this way and allowed to dry for a few minutes, some drops of the sample solution are applied to the upper surface and it is dried at $100^{\circ} \mathrm{C}$ for 15 minutes.

VIEWING IN THE LIGHT MICROSCOPE (See Fig. 1b-d, 2)

The circular cover slip is placed onto a large rectangular glass slide and covered with a rectangular cover slip. The rectangular cover slip is held in place with re-usable adhesive (e.g. blu-tack, double-sided sticking tape etc.) to prevent the circular cover slip from moving during LM analysis. Methanol is introduced into the void between the glass slide and the rectangular cover slip for better penetration of the transmitted light. If oil immersion lenses are used, a drop of immersion oil can be placed on the upper surface of the rectangular cover slip. The position of individual specimens is readily recorded by reference to the grid.

\section{VIEWING IN SCANNING ELECTRON MICRO- SCOPE (See Fig. 1b-d)}

After LM analysis, the rectangular cover slip is carefully removed and discarded, allowing the methanol to evaporate from the circular cover slip containing the nannofossil dispersion. The circular cover slip is then placed on an SEM stub which has been coated with colloidal silver, and is coated and viewed as normal in the SEM (see Fig. 1). Note: The method described here is based upon the use of Cambridge Instruments 'mushroom' type SEM stubs of $13 \mathrm{~mm}$ diameter.

\section{CONCLUSION}

Using a technique for viewing the same specimen in both light microscope and scanning electron microscope is expedient for a number of reasons, e.g. the exact nature of central area characteristics such as grills, bars and spines etc. which may be obscure or indistinct in the LM alone can be determined in the SEM. Also, specimens which have been greatly altered by diagnetic effects may be identified by a combination of their LM and SEM characteristics. Finally, and perhaps most importantly, such a technique provides an ideal opportunity to describe new forms in the most complete way yet possible, thus avoiding misinterpreta- 

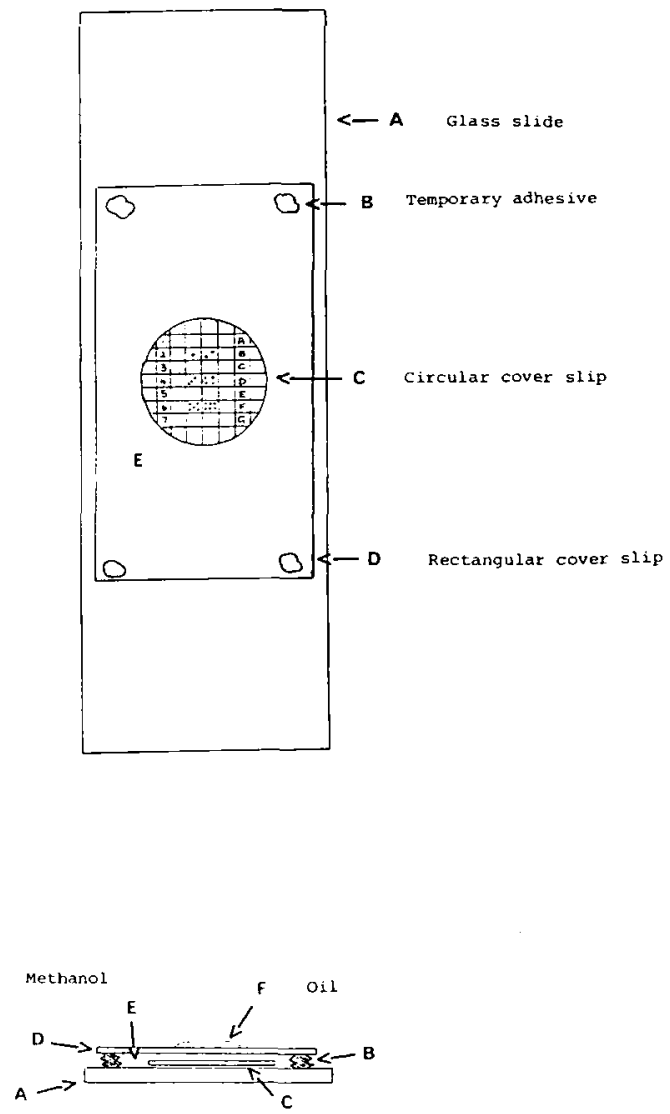

Fig. 2. Sample slide configuration for viewing in the light microscope.

tion of morphological features of taxonomic significance as an artefact of the instrumental viewing medium. This technique is clearly applicable to the study of other small microfossil groups, for example diatoms.

Plate 1 illustrates specimens of various types of calcareous nannofossil and shows how the use of the two viewing mediums (LM \& SEM) most fully reflects the optical and structural properties of each.

\section{ACKNOWLEDGEMENTS}

The author would like to express gratitude to N.E.R.C. for providing the studentship under which this research was carried out, and to Shell U.K. Exploration \& Production, Dr. D. B. Waghorn and Dr. A. R. Lord for provision of sample material. Thanks are also extended to Dr. P. R. Bown and Mrs. J. A. Burnett and Dr. S. Moshkovitz for their help in the development of this technique.

Manuscript received October 1987

Revised manuscript accepted January 1988

\section{REFERENCES}

Laing, J. F. 1974. A specimen location technique for SEM strew mounts. Palaeontology, London, 17(2), 435-436.

Moshkovitz, S. 1974. A new method for observing the same nannofossil specimen both by light microscope and by scanning electron microscope and preservation of types. Israel J. Earth Sci., 23, 145-147.

Moshkovitz, S. 1978. New types of cover slip and mounting slide with a graticule for examination of the same small object both by the light microscope and the scanning electron microscope. Microscopica Acta, 80(2), 161-166.

Perch-Nielsen K. 1967. Eine preparationstechnik zur untersuchung von nonnoplankton in Lichtmikroskop und im Elektronenmikroskop. Meddr. dansk geol. Foren., Copenhagen, 17, 129-130.

Thierstein, H. R., Franz, H. E. \& Roth, P. H. 1971. Scanning electron and light microscopy of the same small object. Micropaleontology, New York 17, 501-502. 